
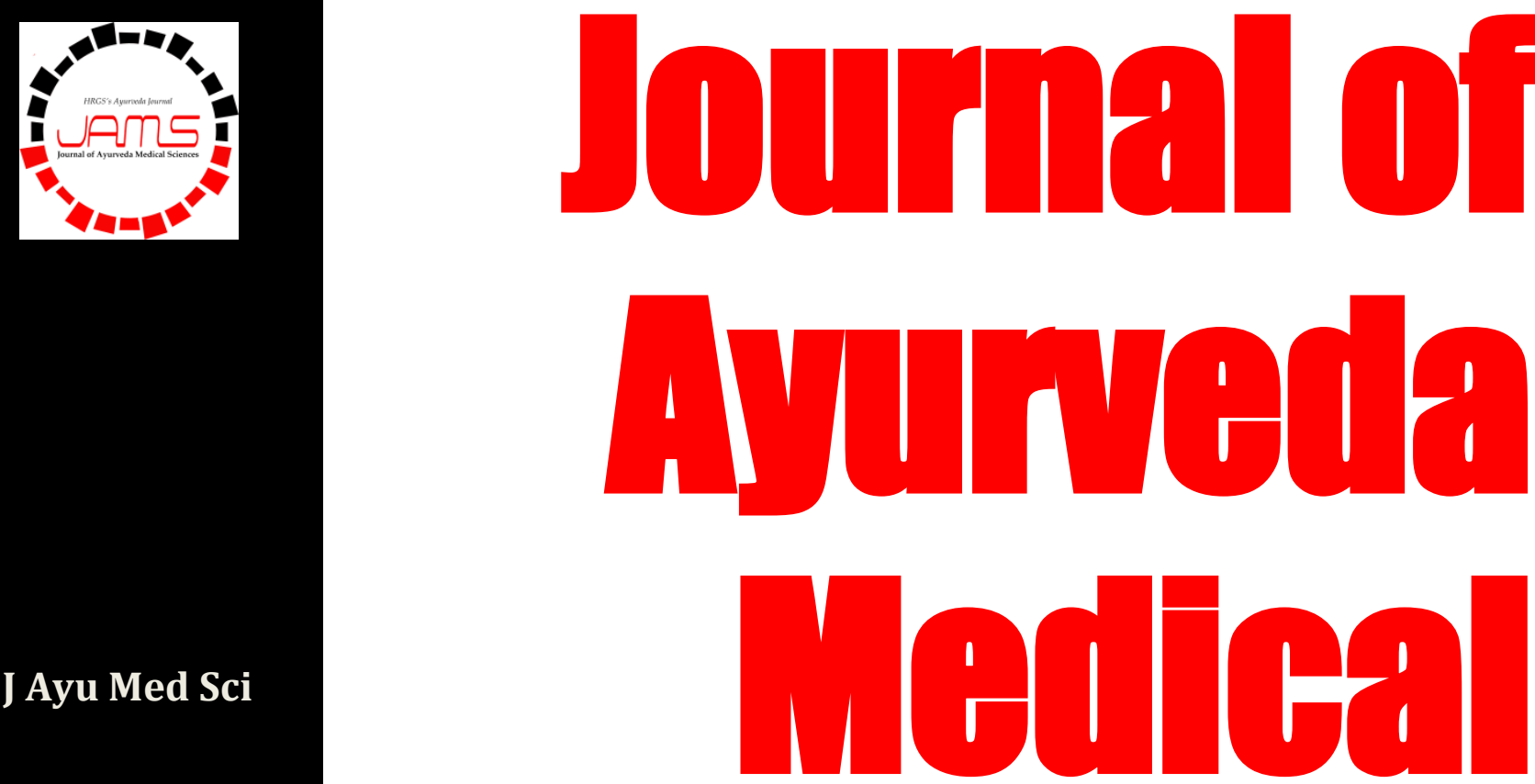

Quarterly Journal for

Rapid Publication

of Researches

in Ayurveda

and Other Traditional

Medicines

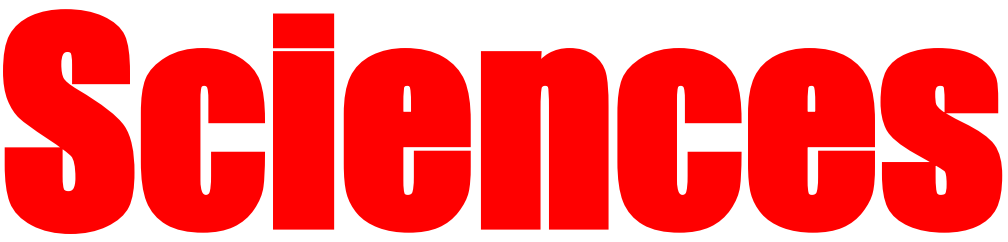

ISSN 2456-4990

www.jayumedsci.com

\title{
Pharmaceutico-Analytical Study Of Tulasi (Ocimum sanctum Linn.) Arka (Hydro-distillate)
}

Tulasi is well known drug for respiratory disorders and it contain $0.4 \%$ volatile oil. Arka Kalpana (Hydrodistillation) is one of important method of extraction and it has more potency. Tulasi arka is used for shwasa, kasa and raktapitta. This study has revealed the organoleptic charcters, physicochemical analysis and GC-MS compositional analysis for use as tool for standardization of the Tulasi Arka.

Rajanna et al. 


\section{Pharmaceutico-Analytical Study of Tulasi (Ocimum sanctum Linn.) Arka (Hydro-distillate)}

Kavyashree Maliyappa Rajanna*, Harini Ashwathanarayana, Prakash Lakshminarayana Hegde, Sunil Kumar Koppala Narayana' Department of Dravyaguna, SDM College of Ayurveda and Hospital Hassan, Karnataka 573201, 'Siddha Central Research Institute, CCRS, Ministry of AYUSH, Anna Hospital Campus, Arumbakkam, Chennai 600106, India.

\section{ABSTRACT}

Introduction: Tulasi (Ocimum sanctum Linn.) of Lamiaceae known as Holy Basillt is commonly available and cultivated across the India and it is having many therapeutic usages and Arkaisan important dosage form because it has good patient compliance, long shelf life and increased potency. TulasiArka is one such Arka used for Shwasa (Asthma), Kasa (Cough) and Hikka (Hicough). Methods: Tulasiarka was prepared using leaves of O.sanctum as per the standard procedure. The prepared Arka was subjected to organoleptic, physiochemical and GCMS study. Results: Analysis of prepared Arka was carried out as per the protocols laid down by Ministry of AYUSH, Govt of India for Arka. 14 chemical compounds were detected in TulasiArka by GCMS Analysis. Conclusion: Organoleptic characters, physiochemical analysis, and GC-MS values can be used as supplement tool for standardization of the TulasiArka.

KEYWORDS Ayurvedic hydro-distillates, TulasiArka, GCMS.

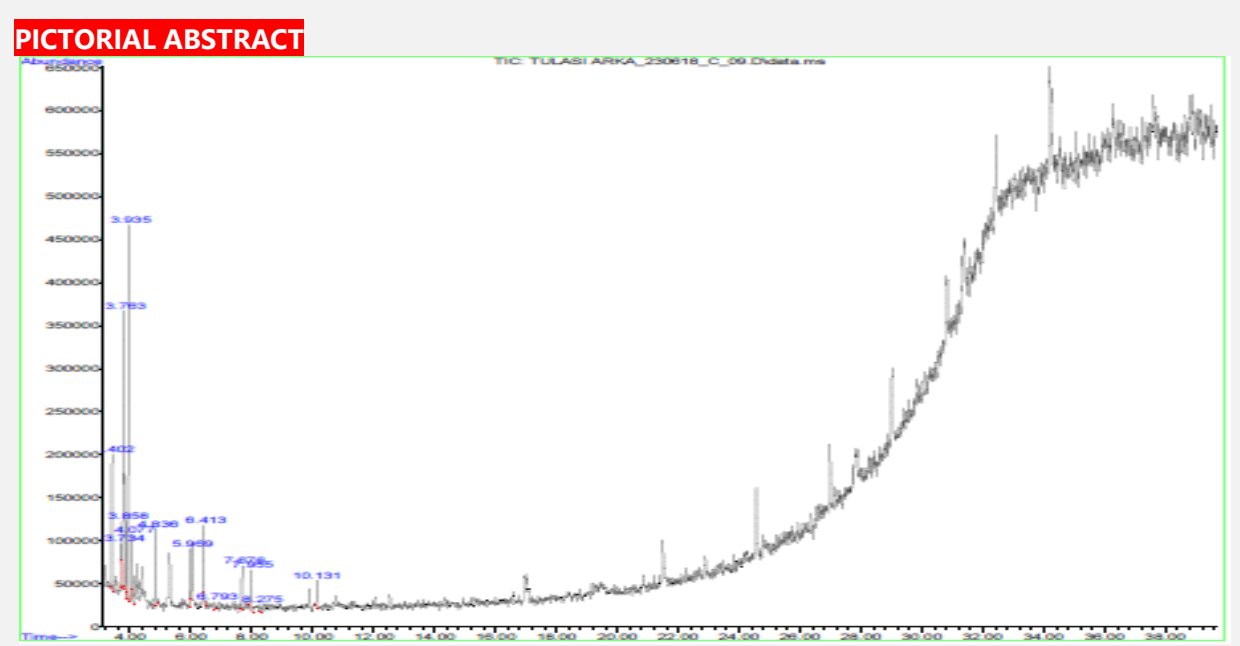

ARTICLE HISTORY Received 16.12.2018 Accepted 30.03.2019

CORRESPONDENCE Dr. Kavyashree MR, Department of Dravyaguna, SDM College of Ayurveda and Hospital Hassan, Karnataka 573201, India. Email: drkavya.mrbams@gmail.com

CITE THIS RESEARCH AS Rajanna KM, Ashwathanarayana H, Hegde PL, Koppala Narayana SK. Pharmaceutico-Analytical Study of Tulasi (Ocimum sanctum Linn.) Arka (Hydro-distillate). J Ayu Med Sci 2017;3(3):424-6.

DOI 10.5530/jams.2018.3.23
Tulasi (Ocimum sanctum Linn.) is perennial herb with an aromatic smell; known as holy basil. It is commonly available and cultivated across the India and it is having many therapeutic usages. Traditionally, the fresh fruit and leaf juice are commonly used in the treatment of cough, Upper respiratory tract infections, and worm infestations ${ }^{[1]}$. It is Katu (Pungent), Tikta (Bitter) rasa, Laghu (Light), Ruksha (Rough), Guna, Usna (Hot) veery and KatuVipaka. It has Kaphavatashamaka. It is useful in the disease such as Hikka, Agnimandya, Kustha,Krimi, Aruchi, Chardi, Jwara, Mukhadourgandhya and Visavikara, and also in Parsvasula, Daha, Raktavikaraha. It has extensive folklore use in Shwasa, Kasa and Jwara etc ${ }^{[2]}$.

Ayurvedic pharmaceutics are dealt under the heading of BhaishajyaKalpana, which basically depends upon the PanchavidhaKasayaKalpana ${ }^{[3]}$. ArkaKalpana is described as one of the Panchavidhakasayakalpna in Arkaprakasha ${ }^{[4]}$. Arka is a liquid preparation obtained by distillation of certain liquids or of drugs soaked in water using the Arkayantra or any convenient distillation apparatus ${ }^{[5]}$. The Arka dosage form is one of the most sought after dosage forms, due to its reduced dose, increased patient compliance. TulasiArka is one such Arka used for Shwasa (Asthma), Kasa (Cough), Raktapitta (Bleeding disorders) ${ }^{[6]}$. In the present study an attempt has been made to standardize the method of TulasiArka and characterize the organoleptic, Physiochemical parameters. In addition, the components in the distillate have been tried to identify using GCMS.

\section{Plant materials}

The fresh Tulasi (OcimumsanctumLinn.) leaves was collected from the Herbal Garden of Shri Dharmashtala Manjunatheshwara College of Ayurveda and Hospital, Hassan, Karnataka and authentication of the Tulasi leaf was done at department of Dravyaguna, Sri Dharmasthala Manjunatheswara College of Ayurveda and Hospital, Hassan based on macroscopic and organoleptic characters. The preparation of TulasiArka was 
done at Department of Rasashastra and Bhaishajyakalpana, Sri Dharmasthala Manjunatheswara College of Ayurveda and Hospital, Hassan as per the reference of general method of preparation of Arka.

\section{Preparation of Arka}

In this study, It was prepared as per one of the ratio of Arka (distillate) is 1:2 ratio. For $50 \mathrm{gms}$ of raw Tulasi Leaves 2 times water was added and this mixture (drug and water) was continuously heated in the ArkaYantra (distillation apparatus) till $60 \%$ of distillate was collected. The vapour condensed and collected in a receiver. In the beginning the vapour consists of only steam and may not contain the essential principles of the drugs. So it was discarded. After cooling, the collected Arka (distillate) is preserved in air tight container.

\section{Analytical Study}

Arka was analyzed with organoleptic parameters like colour, taste, odour, state and physico-chemical characters like $\mathrm{pH}$, specific gravity, refractive index, viscosity and volatile matter and Gcms analysis of Arka.

\section{Physico-chemical parameters}

The samples were analyzed for the organoleptic parameters like colour, taste, odour, state and physical parameters like $\mathrm{pH}$, Specific gravity, and Refractive index by following the method prescribed in Ayurvedic Pharmacopeia of India (API) (Table 1).

\begin{tabular}{|c|c|}
\hline Table 1. Standardization parameters of TulasiArka \\
\hline Parameter & Results \\
\hline Colour & Colourless \\
\hline Odour & Aromatic \\
\hline Taste & Pungent \\
\hline State & Liquid \\
\hline pH & 5.6 \\
\hline Refractive index & 1.33 \\
\hline Specific gravity & 0.99 \\
\hline Viscosity & 0.01 \\
\hline Volatile matter & 0.04 \\
\hline
\end{tabular}

\section{GCMS Analysis}

Gas Chromatography - Mass Spectrometry (GCMS) is the analysis method of choice for separation of Volatile substances or the volatile dervaties of certain non- volatile substances $^{[7]}$. The identification of unknown compounds is achieved by comparison of their full mass spectrum with a mass spectral library or database. The Main limitation of GC-MS is, the compounds must be sufficiently volatile to allow transfer from the solid phase to the mobile carrier gas and thus elute from the analytical column to the detector. Large numbers of compound are still too polar or too large in size to be analyzed with this technique.

Instrument - GC-MS-5975C [AGILENT]. Column Oven Temperature $-70^{\circ} \mathrm{C}$; Injector Temperature $-250^{\circ} \mathrm{C}$; Injection Mode - Split; Split Ratio - 10; Flow Control Mode Linear Velocity; Column Flow -1.5ml /min; Carrier Gas - Helium 99.9995\% purity; Injection volume-1microlitre; COLUMN -DB$5 \mathrm{~ms}$ Agilent; Length $-30.0 \mathrm{~m}$; Diameter $-0.25 \mathrm{~mm}$, Film Thickness -0.25 um.

Column oven temperature program -

$\begin{array}{ccc}\text { Rate } & \text { Temperature }\left({ }^{\circ} \mathrm{C}\right) & \text { Hold Time }(\mathrm{min}) \\ - & 70.0 & 3.0 \\ 10 & 300 & 9.0[35.0 \mathrm{mts} \text { total }]\end{array}$

Ion source temp $-230^{\circ} \mathrm{C}$; Interface temp $-240^{\circ} \mathrm{C}$; Scan range- 40- 700m/z; Solvent cut time- 3mins; MS start time 3(min); MS end time -35 (min); Ionization- EI (-70ev); Scan speed - 2000;MS LIBRARY NIST -11

GCMS Spectrum profile of TulasiArka confirmed the presence of fourteen chemical compounds. All the parameters including name, retention time, and peak area were ascertained from this comparison. The major compound which accorded for $28.36 \%$ was unidentified along with 3 other minor constituents. Other major constituents identified were benzene 1,2,3-trimethyl (23.72\%) and styrene (10.03\%) (Table 2).

\section{Table 2. GCMS Identified compounds of TulasiArka}

\begin{tabular}{|c|c|c|c|}
\hline Peak & Retention Time(RT) & Area \% & Name of the compound \\
\hline 1 & 3.402 & 10.03 & Styrene \\
\hline 2 & 3.734 & 1.56 & -- \\
\hline 3 & 3.763 & 28.36 & -- \\
\hline 4 & 3.858 & 4.34 & Benzene 1,2,3-trimethyl \\
\hline 5 & 3.935 & 23.72 & Benzene,1-ethyl-4-methyl- \\
\hline 6 & 4.077 & 3.83 & Isoborneol \\
\hline 7 & 4.836 & 5.89 & Fumaric acid,2-2dichloroethyl tridecyl ester \\
\hline 8 & 5.969 & 4.06 & Cycloheptasiloxane,tetradecamethyl- \\
\hline 9
\end{tabular}


Rajanna et al. J Ayu Med Sci 2018; Jul-Sep 3(3): 424-6.

\begin{tabular}{c|c|c|c}
\hline 10 & 6.793 & 1.10 & 3-phenyl-2H-chromene \\
\hline 11 & 7.676 & 4.14 & 1H-Imidazole-4-methanol \\
12 & 7.955 & 3.36 & Benzoic acid,2,5bis(trimethylsiloxy)-,trimethylsilyl ester \\
\hline 13 & 8.275 & 1.13 & Cyclohexane,1-1-(2-methyl-1,3propanediyl)bis- \\
\hline 14 & 10.131 & 2.46 & \\
\hline
\end{tabular}

The chemical composition of TulasiArka obtained in the present study is in agreement with the earlier findings reporting that Cyclohexane is found similar of volatile oil produced from the $O$. sanctum ${ }^{[8]}$.

Tulasi is well known drug for respiratory disorders and it contain $0.4 \%$ volatile oil. Arka kalpanā is given specific importance and it has more potency and it can be used even upto one year. Gas Chromatography - Mass Spectrometry (GCMS) is the analysis method of choice for separation of Volatile substances. GCMS of TulasiArka identified 14 compounds. The analytical study gives a preliminary standard of Tulasi Arka.

\section{CONFLICT OF INTEREST Nil}

CONTRIBUTORS Dr Kavyashree contributed to the conceptualization of topic, intellectual study and design of the experiment. Dr Harini and Dr Prakash edited the manuscript, and made the write up suitable for publication. Dr KN Sunil Kumar planned and executed the study, interpreted the result and provided suitable suggestions.

\section{REFERENCES}

1. Hegde L Prakash, A Harini. A Text Book Of DravyaGunaVijnana,Varanasi: Chaukhambha Sanskrit Sansthan.; 2014; p.829.

2. Bhavamishra, Bhavaprakashanighnatu,Hindi commentary by ChunekarKc,Varanasi: ChaukhambhaBharatiya Academy; 2015; p.496.

3. Murthy SKR. SharangadharaSamhita. Varanasi: ChaukhambhaOrientalia; 2012; p.51.

4. Tripathilndradeva. ArkaPrakasha of LankapathyRavana. 2nd ed.Varanasi: ChowkambhaKrishnadas Academy; 2006.

5. The Ayurvedic Formulary of India. Part I. Vol I. $2^{\text {nd }}$ ed. New Delhi: Ministry of Health and Family Welfare, Govt. of India; 2003; p.27, 53.

6. AngadiRavindra. A $\quad$ Text $\quad$ Book Of BhaisajyaKalpanaVijnana(Pharmaceutical Science),Varanasi: ChaukhambaSurbharatiPrakashan; 2016; p.119.

7. U Sathyanarayan, U Chakrapani,Biochemistry,Kolkatta: Books and allied (p) Ltd; 2010; p.721.

8. G. Devendran, U. Balasubramanian. Qualitative phytochemical screening and GC-MS analysis of Ocimum sanctum L. leaves:Pelagia Research Library. Asian Journal of Plant Science and Research; 2011;1(4):44-48 